Article

\title{
Measurements of Water Permeability in Unconsolidated Porous Media with Methane Hydrate Formation
}

\section{Bo Li ${ }^{1,2,3}$, Xiao-Sen $\mathrm{Li}^{1,2, *}$, Gang $\mathrm{Li}^{1,2}$, Jia-Lin Jia ${ }^{1,2,3}$ and Jing-Chun Feng ${ }^{1,2,3}$}

1 Key Laboratory of Renewable Energy and Gas Hydrate, Guangzhou Institute of Energy Conversion, Chinese Academy of Sciences, Guangzhou 510640, China;

E-Mails: libo@ms.giec.ac.cn (B.L.); ligang@ms.giec.ac.cn (G.L.); jiajl@ms.giec.ac.cn (J.-L.J.); fengjc@ms.giec.ac.cn (J.-C.F.)

2 Guangzhou Center for Gas Hydrate Research, Chinese Academy of Sciences, Guangzhou 510640, China

3 University of Chinese Academy of Sciences, Beijing 100083, China

* Author to whom correspondence should be addressed; E-Mail: lixs@ms.giec.ac.cn;

Tel.: +86-20-8705-7037; Fax: +86-20-8703-4664.

Received: 6 May 2013; in revised form: 17 June 2013 / Accepted: 15 July 2013 /

Published: 23 July 2013

\begin{abstract}
Permeability is one of the key factors that determine the fluids flow capacity and production potential of hydrate deposits. In this study, an experimental setup is developed to investigate the flow properties of the porous media, and the permeabilities to water are measured in the unconsolidated porous media with or without hydrate deposition in the pores. A specialized method of precisely controlling the amount of injected methane gas is employed to form methane hydrate in the core sample, and the hydrate formation process is described by the change characteristics of the gas and hydrate saturations. It is found that the residual gas plays an obstructive role in the water flow and it tends to slightly reduce the water permeability in the porous media, especially under high pressure conditions. After hydrate formation in the core sample, relatively steady flow state can be obtained under suitable water injection rate $Q$ at which hydrate dissociation rate is very slow. The absolute permeability of the porous sample is reduced from 49.2 to 1.2 Darcies when the hydrate saturation increases from 0 to $9.3 \%$ in this study, indicating a strong dependence of $k$ on the hydrate saturation.
\end{abstract}

Keywords: permeability; methane hydrate; porous media 


\section{Introduction}

Natural gas hydrates (NGHs) are crystalline solid compounds formed by gas and water molecules combined in a clathrate structure [1]. The water molecules are hydrogen-bonded in the cage and they form polyhedral void spaces for gas occupancy. Under specific geologic conditions (high pressure and low temperature) in Nature, gas hydrates can be formed in huge amounts when the gas and water resources are adequate. To meet the increasing global energy demand, gas hydrates have attracted much attention as a potential energy resource to be investigated widely (from laboratory to reservoir) in the World. Through scientific drilling projects and field-scale research projects, many countries have confirmed the extensive occurrence of gas hydrates in marine sediments and permafrost areas where the geologic conditions are favorable for their formation and stability. It is estimated that the total amount of natural gas trapped in gas hydrates is huge, and it is worth further exploring as a kind of new and challenging energy resource in the future [2,3].

Recent experimental and numerical studies have introduced various kinds of production methods for hydrate dissociation in porous sediments, such as depressurization [4-7], thermal stimulation [8,9], inhibitor injection [10], and their combinations [11,12]. The idea of producing hydrocarbons from gas hydrates through $\mathrm{CO}_{2}$ injection has also attracted much attention as it not only can realize the use of natural gas but also may sequestrate the $\mathrm{CO}_{2}$ as gas hydrates in sediments [13,14]. It is demonstrated that the commercial viability of in situ gas hydrate exploitation is affected by many geologic parameters, one of which is the permeability of the porous sediments. As one of the key factors that determine the production potential of the hydrate reservoir, the effective permeability $k_{\text {eff }}$ of each phase in the hydrate-bearing sediments reflects the ability of fluids to migrate in the porous media and also affects the heat and mass transfer rates among different phases (gas, water, hydrate, and sediment grain). Numerical studies $[11,15]$ have shown that coarse porous media characterized by high intrinsic permeability would facilitate the hydrate dissociation, and the exploitation potential will then be more desirable. However, the $k_{\text {eff }}$ of the hydrate deposits may be reduced to an extremely low level when the hydrate saturation $S_{\mathrm{H}}$ is high. In other words, $k_{\mathrm{eff}}$ decreases with the increase of $S_{\mathrm{H}}$ due to the reduction of void space available for fluids flow during the hydrate deposition in the pores.

The permeability change characteristics depend on the sediment grain properties, the porosity change, the evolution of hydrate saturations, and so on [16]. Generally, the fluid transportation ability of the porous media will be reduced profoundly when part of the pores are deposited with other solid phases (such as chemical precipitation or freezing of pore fluids). Previous studies indicate that the dependences of permeability $k$ on porosity $\phi$ and hydrate saturation $S_{\mathrm{H}}$ can be simply formulized as [17]:

$$
k=k_{0}\left(\frac{\phi}{\phi_{0}}\right)^{n}=k_{0}\left(1-S_{H}\right)^{n}
$$

where $k_{0}$ is the absolute permeability without hydrates, $\phi_{0}$ is the initial porosity, and $n$ is the reduction factor representing the dependence of permeability on porosity or hydrate deposition. If hydrate particles are deposited uniformly around the sediment grains, or are preferentially deposited in the throats of the pore channels [16], then the permeability will be reduced dramatically, even under minor amount of hydrate deposition. Besides, the capillary pressures $P_{\text {cap }}$ also have effects on the water 
permeability, and their relationship can be theoretically presented as [18]:

$$
P_{c a p}=\sqrt{\frac{k_{0}}{k} \frac{\phi}{\phi_{0}}} P_{c a p, 0}
$$

where $P_{\text {cap }, 0}$ is the capillary pressure under the reference conditions (at which the permeability and porosity are $k_{0}$ and $\phi_{0}$, respectively). Formation of solid hydrate will generally reduce the pore size of the porous media, and thereby result in larger capillary pressures. Then the permeability will be decreased because of the increased capillary pressure.

Current permeability reduction models are mainly based on the experimental and theoretical studies of the relationship between the porosity and the permeability when the pore space is partly filled by solids. Direct measurements of the intrinsic permeability in the hydrate-bearing sediments are difficult, which is due to the following reasons: (1) the effective pores are usually filled with two mobile and immiscible phases (gas and water) after hydrate formation, and it is very hard to completely displace one phase with another to obtain the intrinsic permeability; (2) the hydrate stability may be broken down under successive disturbance of water or gas flooding; (3) the hydrate is usually distributed nonuniformly in the pores, and it may completely block the flow channel in some local area to inhibit the fluid flow through the porous media.

Up to now, many researchers have investigated the flow properties of the porous media with hydrate formation using different methods. Based on the permeability model shown in Equation (1), Minagawa et al. [19] carried out water permeability measurements in methane hydrate-bearing sediments. The reduction factor $n$ was found to be about 9.8 with $S_{\mathrm{H}}$ larger than $10 \%$ in the artificial Toyoura sand, and the value increased when the $S_{\mathrm{H}}$ was below 10\%. Kumar et al. [20] performed a series of experiments to measure the gas permeability in the $\mathrm{CO}_{2}$ hydrate sediments, and found that hydrate tended to form on the grain surfaces for initial water saturations less than $35 \%$, while a pore-filling tendency was indicated for water saturations above 35\%. Sakamoto et al. [21] investigated the permeability change behaviors during hydrate dissociation and gas production. The absolute permeability of the hydrate-bearing sediments was obtained by assuming that the relative permeability to water $k_{\mathrm{rw}}$ was constant and independent of hydrate saturation under the residual gas saturation condition. Johnson et al. [22] measured both the absolute permeability and the relative permeability in the unconsolidated hydrate-bearing samples from the Mount Elbert test well. Experimental results showed that the permeability of porous media would be significantly reduced under low to moderate hydrate saturations $(1.5 \%$ to $36 \%)$. The absolute permeability may also be assessed using the microfocus X-ray computed-tomography (CT) system [23] or estimated from the NMR spectra based on the SDR model [24]. No matter what kind of permeability needs to be measured (absolute

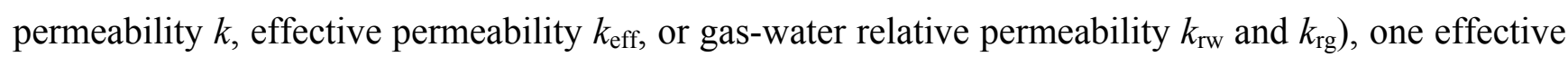
and reliable way is to carry out flow experiments in porous media.

In this study, we investigated the relationship between the effective water permeability and the hydrate saturation in unconsolidated hydrate-bearing sediments using a novel and more accurate method. The most effective technique for laboratory permeability measurement is the flow experiment, and we have established an experimental apparatus specifically for the understanding of the fluids flow and the permeability change characteristics in hydrate-bearing sediments. In order to reduce the inhibition effect of the gaseous phase on the water flow, the gas saturation is decreased below a 
desired low level by injecting water multiple times during the hydrate formation process. During all the flow experiments, we try to obtain the steady state of water flow with the single aqueous phase in the core holder. This is because unsteady state flow experiments may produce piston-like displacement when the effective pores are filled with different mobile and immiscible phases [22], and the unsteady state flow may prevent precise measurements during the complicated multiphase flow process.

\section{Experimental Apparatus}

Figure 1 shows the schematic design of the experimental setup used in this study for the effective water permeability measurements within the hydrate-bearing sediments. A cylindrical core holder that can withstand a maximum pressure of $25 \mathrm{MPa}$ is fixed vertically in a water bath $\left(-5-20{ }^{\circ} \mathrm{C}, \pm 0.1{ }^{\circ} \mathrm{C}\right)$. The effective volume of the holder is measured to be $81.8 \mathrm{~mL}$ with water displacement (250 $\mathrm{mm}$ in length and $20 \mathrm{~mm}$ in diameter). Three Pt100 thermocouples $\left(-15-90{ }^{\circ} \mathrm{C}, \pm 0.1{ }^{\circ} \mathrm{C}\right.$ ) are inserted into the internal surface of the vessel to monitor the temperature change during the hydrate formation and water flow experiments. The system pressure is measured by two pressure transducers (0-25 MPa, $\pm 0.1 \%$ ) which are located at the inlet (bottom side) and the outlet (top side) of the core holder, respectively. A Honeywell ST3000 smart pressure transducer $(-100-100 \mathrm{KPa}, \pm 0.25 \%)$ is used to measure the differential pressure between the two sides of the core holder. There are some small grooves distributed in the internal surface of the core holder to insure that the sediment grains could be attached to the surface closely.

Figure 1. Schematic of the experimental apparatus.

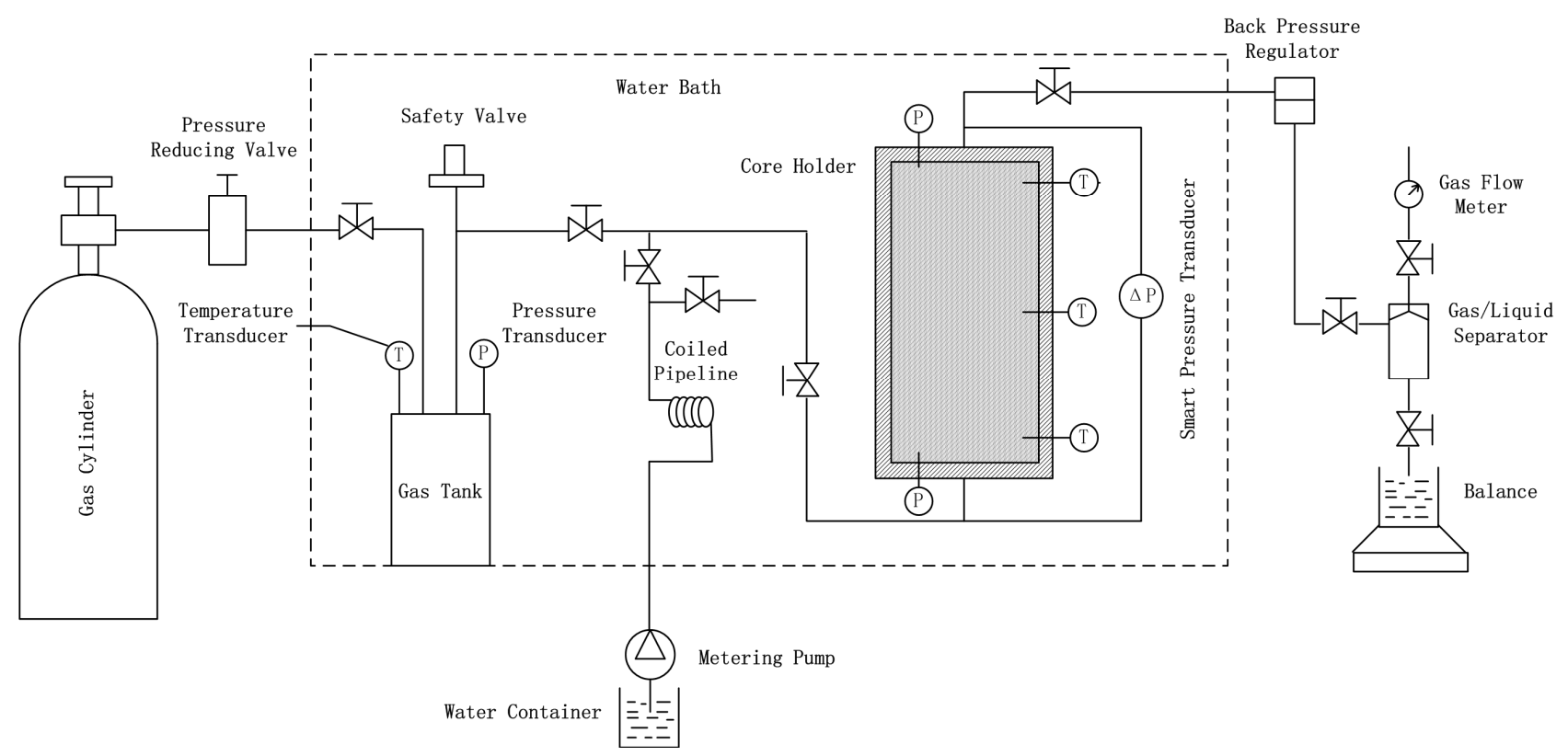

Another stainless gas tank with an effective volume of $251.5 \mathrm{~mL}$ is located at the inlet of the core holder, as shown in Figure 1. It is used to accurately control the amount of the methane gas injected to the holder. The pressure and temperature of the gas tank are measured by another pressure transducer and Pt100 thermocouple placed inside it, respectively. A Beijing Chuangxintongheng HPLC P3000 metering pump (Chuangxintongheng, Beijing, China) with a range of $1-50 \mathrm{~mL} / \mathrm{min}$ and the maximum pressure of up to $30 \mathrm{MPa}$ is used to inject the deionized water with a constant rate. A five-meter long 
pipeline is coiled and fixed in the water bath to precool the injected water. During the flow experiment, the system pressure is controlled by a back-pressure regulator which is connected to the outlet of the core holder. A gas flow meter (D07-19B, 0-1 L/min, $\pm 1 \%$ from Seven Star Company, Beijing, China) and an electronic weighing balance (Sartorius BSA 2202S, 0-2200 g, $\pm 0.01 \mathrm{~g}$, Sartorius, Beijing, China) are situated in the downstream of the back-pressure regulator to monitor the fluids flow rates.

\section{Experimental Procedure}

A total of $125.2 \mathrm{~g}$ raw dry quartz sand with a $300-450 \mu \mathrm{m}$ size range was tightly compacted in the core holder. Then the deionized water was injected into the holder at a constant rate (e.g., $10 \mathrm{~mL} / \mathrm{min}$ ) by the metering pump for more than $30 \mathrm{~min}$, during which a constant differential pressure was observed and the pores of the quartz sand were completely filled with water. The volume difference between the injected and the accumulated water was about $35.0 \mathrm{~mL}$, which was considered as the effective pore volume of the packed sample. Based on the quartz sand density of about $2.65 \mathrm{~g} / \mathrm{mL}$, the calculated pore volume was $34.6 \mathrm{~mL}(=81.8-125.2 / 2.65)$, which was very close to the direct measurement result, so the porosity of the sample was determined to be $42.8 \%$, thus matching the value used in previous studies [7,11].

Then the intrinsic permeability of the porous media was measured without the presence of hydrate by carrying out the flow experiment with different water injection rates. Considering that the system pressure $P$ should be kept above the equilibrium pressure $P_{\text {eq }}$ during the flow process in the presence of hydrate, three different cases were studied by applying the following pressures to the back-pressure regulator to investigate the dependence of the intrinsic permeability on the system pressure: $0,6.5$ and 15.5 MPa. After that, some of the water was withdrawn from the core holder by methane gas displacement, and a predetermined amount of methane gas was injected into the sand from the gas tank. Next, deionized water was injected once again to raise the pressure to a higher level (15-25 MPa) that was more favorable for hydrate formation. Both the gas and water are injected from the bottom of the core holder. As the pressure vessel is placed vertically in the water bath, the methane gas will tend to accumulate in the upper part of the vessel due to buoyancy. This fact may result in non-uniform hydrate distribution in the system. Based on the injected water mass information, the pressure and temperature change of the system, we could theoretically calculate the effective gas volumes before and after the water injection, as well as the number of moles of methane gas present in the holder. Then the temperature of the water bath was decreased to the desired point $\left(8^{\circ} \mathrm{C}\right)$, at which the corresponding equilibrium pressure was calculated to be about 5.7 $\mathrm{MPa}$. The hydrate formation process was started, and it usually lasted for several days. When the descent speed of the inlet and outlet pressure declined during the formation, additional cool water was injected into the core holder to maintain a high pressure driving force for hydrate formation.

When the system pressure nearly stopped decreasing, even under high pressure conditions, the hydrate formation process was halted, and the following procedure was carried out to measure the effective water permeability of the porous media in the presence of hydrate. First, the outlet valve of the core holder was opened and the system pressure was gradually decreased to the predetermined level by the back-pressure regulator. Second, the inlet valve was opened and cool deionized water 
without methane concentration was injected by the metering pump with a relatively slow rate through the coiled pipeline to the hydrate-bearing sample. Third, when both the water injection and production maintained stable, the effective water permeability could be calculated according to the Darcy's Law shown in Equation (3):

$$
k=\frac{\mu Q L}{\pi r^{2} \Delta P}
$$

where $Q$ is the water flow rate $\left(\mathrm{m}^{3} / \mathrm{s}\right) ; L$ is the length of the core holder $(\mathrm{m}) ; \mu$ is the viscosity of water $(\mathrm{Pa} \cdot \mathrm{s}) ; r$ is the radius of the core holder $(\mathrm{m}) ; \Delta P$ is the differential pressure across the quartz sand $(\mathrm{Pa})$; and $k$ is in $\mathrm{m}^{2}$.

After a long enough flow process, the differential pressure gradually decreased to such a low level that the hydrate was thought to have been completely dissociated. Then the flow experiment was terminated. During the whole experiment period, the pressures and temperatures of the core holder as well as other related data were recorded by the data acquisition system at $10 \mathrm{~s}$ intervals. The movement of the hydrate in the core holder was neglected during the flow experiment due to its solid properties.

\section{Results and Discussion}

\subsection{Intrinsic Permeability without Hydrates}

Figure $2 \mathrm{a}, \mathrm{b}$ shows the dependences of the differential pressure $\Delta P$ and the intrinsic permeability $k$ of the core sample on the water injection rate $Q$ and the system pressure $P$, respectively. Three cases are performed with $P=0,6.5$ and $15.5 \mathrm{MPa}$, respectively. The water injection rate increases from 10 to $50 \mathrm{~mL} / \mathrm{min}$ in each case. Generally, each case shows fine linear relationship between $Q$ and $\Delta P$, and the differential pressure nearly keeps the same under different system pressures at the same injection rate, as shown in Figure 2a. This indicates that the fluid flow in the core holder follows Darcy's flow regime, and the system pressure has little effect on the water flow state in the porous media (especially under low $Q$ conditions). The difference of $\Delta P$ at high injection rates (about $Q>30$ $\mathrm{mL} / \mathrm{min}$ ) under different system pressures may be caused by the compression effect of the residual gas in the pores. When the system is pressurized from 0 to $6.5 \mathrm{MPa}$ and further to $15.5 \mathrm{MPa}$, the residual gas is compressed and the gas viscosity increases, resulting in larger viscous effect on the water flow. However, this deviation is not obvious when the injection rate is controlled within a proper level (e.g., $30 \mathrm{~mL} / \mathrm{min}$ in this study).

Based on the $\Delta P$ data, the intrinsic permeability $k_{0}$ of the porous media is calculated according to Equation (3). The characteristics of $k_{0}$ under different injection rates and system pressures are shown in Figure 2b. As expected, the three curves are very close with each other, and they are nearly parallel with the $x$-axis. The slight decrease of $k_{0}$ under high pressures is also caused by the compression effect of the residual gas when its viscous effect becomes more obvious, as discussed above. The average $k_{0}$ of the three cases is 49.2 Darcies, and it is determined to be the intrinsic permeability of the porous media without hydrate formation in this study. 
Figure 2. Characteristics of (a) the differential pressure; and (b) the intrinsic permeability under different injection rates and system pressures.

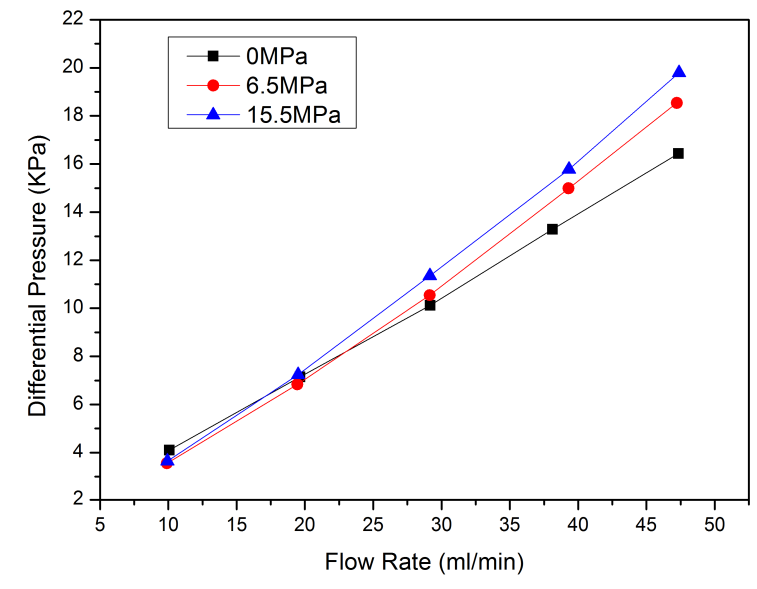

(a)

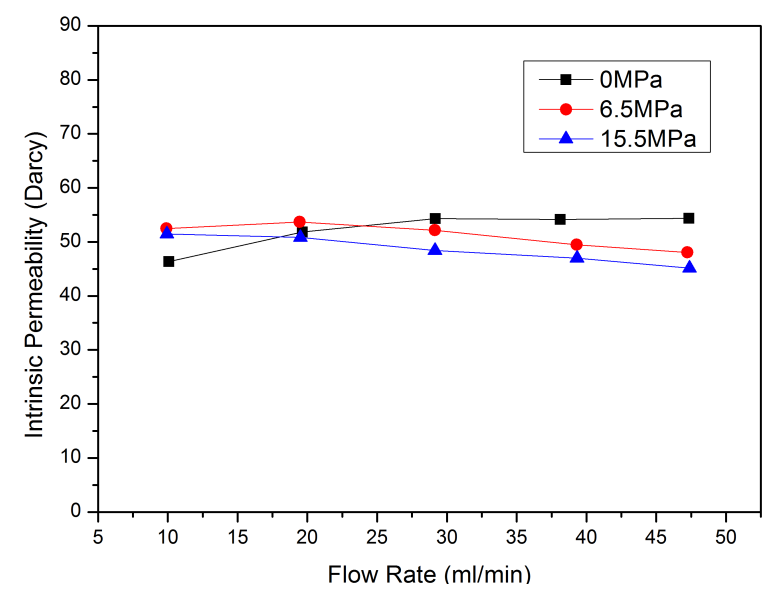

(b)

\subsection{Hydrate Formation}

The hydrate formation experiment is carried out after the intrinsic permeability measurements. Methane gas is injected into the core sample from the gas tank after some water is removed from the core holder through gas displacement. The amount of the injected methane gas $\Delta n_{1}(\mathrm{~mol})$ is calculated by Equation (4):

$$
\Delta n_{1}=V_{\text {tank }} / V_{\mathrm{g} 1}-V_{\text {tank }} / V_{\mathrm{g} 2}
$$

where $V_{\text {tank }}$ is the volume of the gas tank $(\mathrm{mL}) ; V_{\mathrm{g} 1}$ and $V_{\mathrm{g} 2}$ are, respectively, the mole volume of gas in the tank before and after the injection $(\mathrm{mL} / \mathrm{mol})$. After the gas injection stage, the system pressure $P$ rises from 0.68 to $6.15 \mathrm{MPa}$. Then the gas tank is closed, and $P$ is raised from 6.15 to 17.61 $\mathrm{MPa}$ through additional water injection. The total volume of the additionally injected water is $\Delta V_{\mathrm{w}}=13.95 \mathrm{~mL}$. Assuming the incompressibility of water under high pressures, the following equations can be established:

$$
\begin{gathered}
\Delta n_{2}=V_{\text {porel }} / V_{\mathrm{m} 2}-V_{\text {pore1 }} / V_{\mathrm{m} 1} \\
V_{\text {pore1 }} / V_{\mathrm{m} 2}=V_{\text {pore2 }} / V_{\mathrm{m} 3} \\
V_{\text {pore1 }}-\Delta V_{\mathrm{w}}=V_{\text {pore2 }}
\end{gathered}
$$

where $\Delta n_{2}$ is the mole number of the injected methane gas from the gas tank (mol, theoretically equal to $\left.\Delta n_{1}\right) ; V_{\text {pore1 }}$ and $V_{\text {pore2 }}$ are the effective pore volumes for gas accumulation before and after the water injection, respectively $(\mathrm{mL}) . V_{\mathrm{m} 1}$ and $V_{\mathrm{m} 2}$ are the mole volumes of gas in the holder before and after the gas injection, respectively, while $V_{\mathrm{m} 3}$ is the mole volume of gas after the water injection $(\mathrm{mL} / \mathrm{mol})$. All the mole volumes of gas are determined using the Peng-Robinson equation through $P$ and $T$ measurements shown in Table 1. According to these data, all the important unknown parameters in Equations (4)-(7) are solved to be: $\Delta n_{1}=0.0539 \mathrm{~mol}, \Delta n_{2}=0.0565 \mathrm{~mol}, V_{\text {pore }}=20.20 \mathrm{~mL}$ and $V_{\text {pore2 }}=6.25 \mathrm{~mL}$. The deviation of $\Delta n_{2}$ from $\Delta n_{1}$ is less than $5 \%$, indicating the reliability of this method for controlling and precisely computing the amount of the injected hydrate-forming gas. The final determination of the total gas in the holder is $n_{0}=\left(\Delta n_{1}+\Delta n_{2}\right) / 2+V_{\text {porel }} / V_{\mathrm{ml}}=0.0612 \mathrm{~mol}$ 
(1.371 L in standard state).

Table 1. Temperature and pressure data for calculating the mole number of the injected gas and the effective gas volume.

\begin{tabular}{ccccc}
\hline Stage & Device & $\boldsymbol{P}(\mathbf{M P a})$ & $\boldsymbol{T}(\mathbf{K})$ & $\boldsymbol{V}_{\text {gas }}(\mathbf{m L} / \mathbf{m o l})$ \\
\hline \multirow{2}{*}{ Before gas injection } & Gas tank & 6.61 & 281.20 & 297.77 \\
\cline { 2 - 5 } & Core holder & 0.68 & 281.22 & 337.59 \\
\hline \multirow{2}{*}{ After gas injection } & Gas tank & 6.24 & 281.13 & 318.06 \\
\cline { 2 - 5 } & Core holder & 6.15 & 281.16 & 323.46 \\
\hline \multirow{2}{*}{ After water injection } & Core holder & 17.61 & 281.31 & 100.12 \\
\hline
\end{tabular}

Figure 3 shows the evolutions of the inlet and outlet pressure during the hydrate formation process. It can be seen that the pressure decreases sharply in the early stage $(t<1000 \mathrm{~min})$, indicating a relatively high gas consumption rate. Then the decent speed slows down, and another $2.15 \mathrm{~mL}$ water is injected into the core holder to raise the pressure to about $P=20.90 \mathrm{MPa}$ at $t=4320 \mathrm{~min}$. It is aimed to keep the pressure driving force at a high level and to reduce the effective gas volume. However, the rate of pressure decent in Figure 3 seems not to increase obviously after the second water injection, which may be caused by the decreased gas-water contact area. When the pressure nearly stops decreasing, the hydrate formation is ended, and the phase saturations are calculated using the following method.

Figure 3. Evolutions of the inlet and outlet pressure during the hydrate formation.

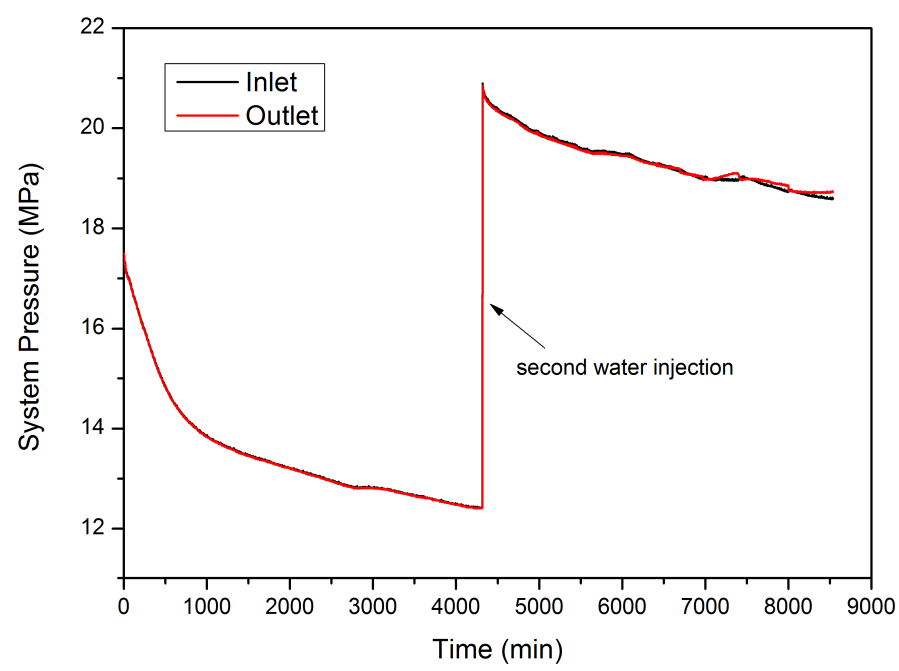

Assuming the incompressibility of the sand grains, the total pore volume $V_{\text {pore }}$ of the core holder remains constant $(35.0 \mathrm{~mL})$ at any time point during the hydrate formation. $V_{\text {pore }}$ can be expressed as:

$$
V_{\text {pore }}=V_{\mathrm{H}}+V_{\mathrm{G}}+V_{\mathrm{W}}
$$

where $V_{\mathrm{H}}, V_{\mathrm{G}}$, and $V_{\mathrm{W}}$ are the volumes of the hydrate, gas, and water present in the core holder, respectively. At time $t$, they are calculated in the following equations:

$$
\begin{gathered}
V_{\mathrm{G}}=V_{\mathrm{gas}} \cdot n \\
V_{\mathrm{W}}=V_{\mathrm{W} 0}+\Delta V_{\mathrm{w}}-N_{\mathrm{H}}\left(n_{0}-n\right) M_{\mathrm{W}} / \rho_{\mathrm{W}}
\end{gathered}
$$




$$
V_{\mathrm{H}}=\left(n_{0}-n\right) M_{\mathrm{H}} / \rho_{\mathrm{H}}
$$

where $V_{\text {gas }}$ is the mole volume of methane gas $(\mathrm{mL} / \mathrm{mol}) ; n_{0}$ is the initial amount of gas at the beginning of hydrate formation (mol); $n$ is the remaining gas during hydrate formation (mol); $V_{\text {Wo }}$ is the initial volume of water $(\mathrm{mL}) ; \Delta V_{\mathrm{w}}$ is the additionally injected water during hydrate formation ( 0 and $2.15 \mathrm{~mL}$ before and after $t=4320 \mathrm{~min}$, respectively); $N_{\mathrm{H}}$ is the hydration number $(5.75) ; M_{\mathrm{W}}$ and $M_{\mathrm{H}}$ are the mole mass of water and hydrate, respectively $(\mathrm{g} / \mathrm{mol}) ; \rho_{\mathrm{W}}$ and $\rho_{\mathrm{H}}$ are the density of water and hydrate, respectively $(\mathrm{g} / \mathrm{mL})$.

Based on the Peng-Robinson equation of state, the evolutions of hydrate and gas saturations $\left(S_{\mathrm{H}}\right.$ and $S_{\mathrm{G}}$ ) during the formation stage are calculated by solving Equations (8)-(11) simultaneously, and they are plotted in Figure 4. It is shown that the hydrate formation rate is very fast in the early $1000 \mathrm{~min}$, corresponding to the time when the system pressure decreases sharply in Figure 3. Then it declines to a relatively stable level in the following period. After the second water injection is finished at $t=4320 \mathrm{~min}$, small amount of hydrate is dissociated because of the disturbance brought by the injected water, and a small decline is observed in the $S_{\mathrm{H}}$ curve. Then it keeps on increasing and finally reaches $9.3 \%$ at the end of the formation process. Though the second water injection seems to have little effect on $S_{\mathrm{H}}, S_{\mathrm{G}}$ is greatly reduced due to the compression effect caused by the injected water. When the formation stage is terminated, $S_{\mathrm{G}}$ declines to the minimum of about $9.7 \%$. That is to say, in order to reduce the obstructive effect of the gaseous phase on the water flow, this method could be employed to control the gas saturation below a desired low level.

Figure 4. Evolutions of the calculated hydrate and gas saturations during the hydrate formation stage.

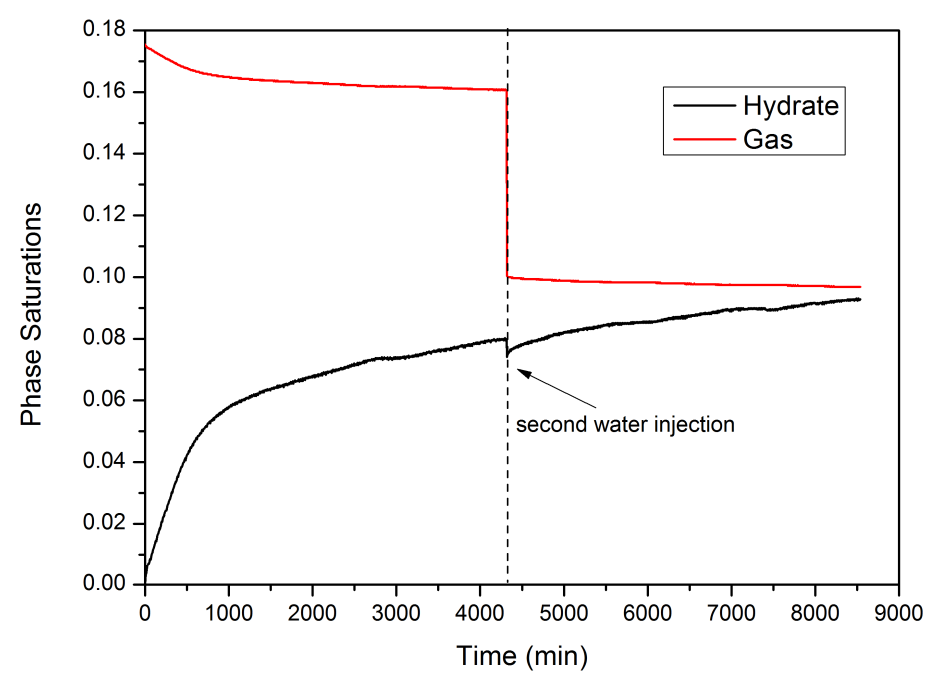

\subsection{Effective Water Permeability Measurements}

After the hydrate formation stage is ended, the flow experiment is then carried out to measure the effective water permeability of the hydrate-bearing sediments. System pressure is firstly decreased from 18.6 $\mathrm{MPa}$ to $15.5 \mathrm{MPa}$ by the back-pressure regulator. Mass release from the core holder during this process is not observed at the outlet balance, which may be because of the limited gas remaining in the system. Then cold deionized water is injected into the core holder at constant rates of 
5,7 and $10 \mathrm{~mL} / \mathrm{min}$, respectively, in three stages. Figure 5 shows the temperature profiles of the core holder during the flow process. It is shown that the temperatures at different measuring points fluctuate regularly (around $8.0{ }^{\circ} \mathrm{C}$, mainly caused by the heat transfer from the surroundings), and they are all lower than the equilibrium temperature (about $16.6^{\circ} \mathrm{C}$ ) at the working pressure of $15.5 \mathrm{MPa}$.

Figure 5. Temperature profiles of the core holder during the flow process.

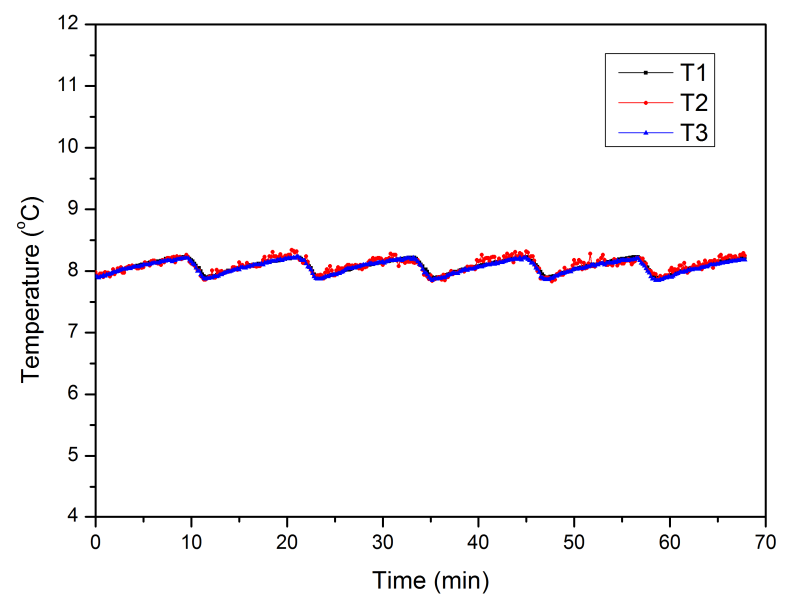

Figure 6 shows the evolution of the differential pressure under different water injection rates in the flow process. In Stage I (0-26 $\mathrm{min})$, the $Q$ is set to be $5 \mathrm{~mL} / \mathrm{min}$, and it remains relatively stable in this period. The deionized water is initially cooled to about $2{ }^{\circ} \mathrm{C}$. When the concentration of methane gas is lower than the solubility limit in the surrounding water, the hydrate crystal tends to break down and release methane by dissolution (even if the pressure and temperature conditions are still favorable for hydrate stability) [25].

Figure 6. Evolution of the differential pressure under different water injection rates in the flow process.

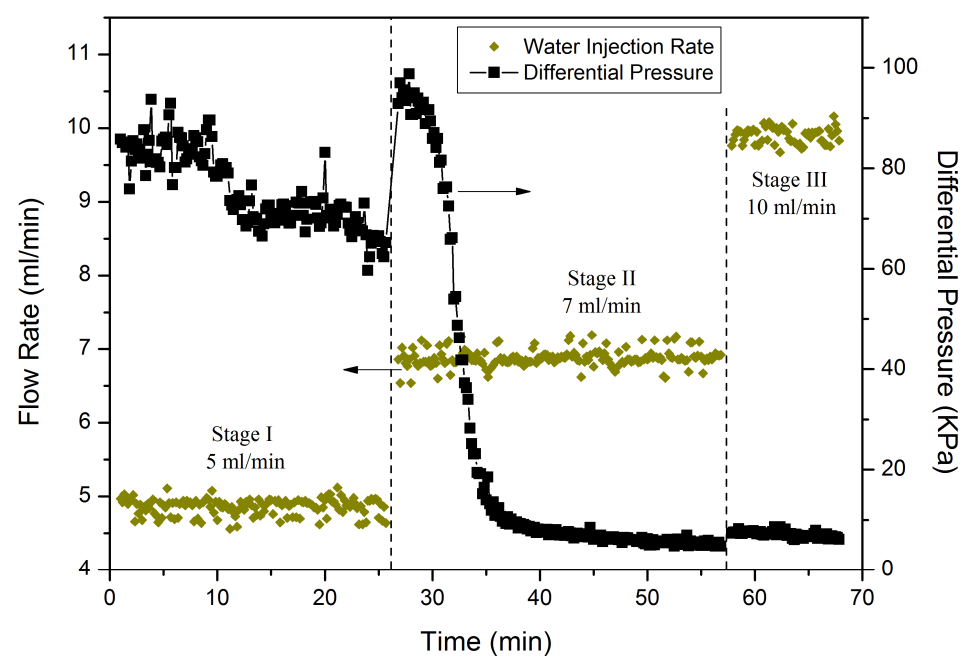

When the deionized water is injected, the balance between the hydrate and the dissolved methane in the initial system is broken down, and gas is released from hydrate dissolution. In other words, the amount of solid hydrate will gradually decrease under successive water injection conditions, and the 
flow will become easier with the hydrate dissolution into the water phase. That is why a slight decline of $\Delta P$ is observed during Stage I. On the other hand, the speed of decrease of $\Delta P$ is very slow in this period because of the small $Q$ and the low initial temperature of the injected water. Stage I can be approximately thought to be a steady state flow process.

As soon as the $Q$ is raised to $7 \mathrm{~mL} / \mathrm{min}$ in Stage II, $\Delta P$ is rapidly increased to a higher level, which indicates a strong dependence of $\Delta P$ on $Q$. However, after a short stabilization period, it declines sharply to an extremely low level of about $\Delta P=10 \mathrm{KPa}$ in less than $10 \mathrm{~min}$, indicating larger hydrate dissociation rate under higher $Q$. This is because: (i) the temperature of the water container (Figure 1) has risen approximately to the room temperature because of the heat transfer during Stage I, and the injected water may take more additional heat into the system to promote the hydrate dissociation; (ii) higher $Q$ will drive away the dissolved and the free gas more quickly, resulting in faster hydrate dissolution rate in the water phase. After this sharp decrease process, the rate of decrease of $\Delta P$ slows down, indicating complete hydrate dissociation and a gas displacement process by water in the remaining time of Stage II.

When the $Q$ is raised from 7 to $10 \mathrm{~mL} / \mathrm{min}$ in Stage III, a very slight increase of $\Delta P$ is obtained, which further confirms that the hydrate has been totally decomposed under the effect of water injection during Stages I and II. The effective pores of the core holder are only occupied by the water and gas phases. Consequently, the flow experiment is terminated after Stage III lasts for about $10 \mathrm{~min}$. Generally, in order to obtain a steady flow process in the hydrate-bearing sediments, it is necessary to control the water injection rate at a proper level to reduce the hydrate dissolution and dissociation rate.

Based on the $Q$ and $\Delta P$ data, the effective water permeability $k_{\text {eff }}$ of the hydrate-bearing porous media is calculated according to Equation (3). Figure 7 shows the change characteristics of the water $k_{\text {eff }}$ and the cumulative volume of the produced gas $V_{\mathrm{P}}$ during the flow process. When the injection rate is set to be $5 \mathrm{~mL} / \mathrm{min}$ in Stage I, the flow process is approximately in a steady state, as discussed above, so the $k_{\text {eff }}$ nearly remains stable in this period. As the gas saturation is very low (9.7\%) and there is nearly no gas flow in this stage, the $k_{\text {eff }}$ of water can be approximately considered as the absolute permeability with the hydrate saturation $S_{\mathrm{H}}=9.3 \%$. Comparing with the intrinsic permeability shown in Figure $2 b$, the absolute permeability $k$ of the porous sample has decreased from 49.2 to 1.2 Darcies. Such a steep decrease of permeability at low hydrate saturation is caused by the decrease of the effective porosity in the porous media, as shown in Equation (1), and it also indicates that the hydrate particles tend to be firstly deposited in the throats of the pores. After the $Q$ is raised to $7 \mathrm{~mL} / \mathrm{min}$, the $k_{\text {eff }}$ changes little in the first several minutes, and the gas production still remains at 0 , indicating little hydrate dissociation. However, as soon as the released gas is produced from the core holder, the hydrate dissociation gradually becomes notable, and the effective permeability of water increases continuously with time, as shown in Figure 7. This indicates that the flow channel previously blocked by the hydrate has been completely opened during water flooding. The decreasing trend of the gas production rate indicates that hydrate in the pores has been completely dissociated at the end of Stage II, and the produced gas is from the free gas displaced by water flow. When the $Q$ is further increased to $10 \mathrm{~mL} / \mathrm{min}$ in Stage III, the $k_{\text {eff }}$ shows the same increasing trend as that in Stage II, and the gas displacement rate changes little. At the end of the flow experiment, the effective permeability has risen to about 30 Darcies, which is very close to the intrinsic permeability of the porous media without hydrate. The difference between them is also caused by the interference of the compressed 
residual gas in the sample. It can be predicted that after a long enough displacement process, more free gas will be driven out of the core holder and the effective permeability will finally increase to the intrinsic permeability shown in Figure $2 b$.

Figure 7. Change characteristics of the water $k_{\text {eff }}$ and the cumulative volume of the produced gas $V_{\mathrm{P}}$ during the flow process.

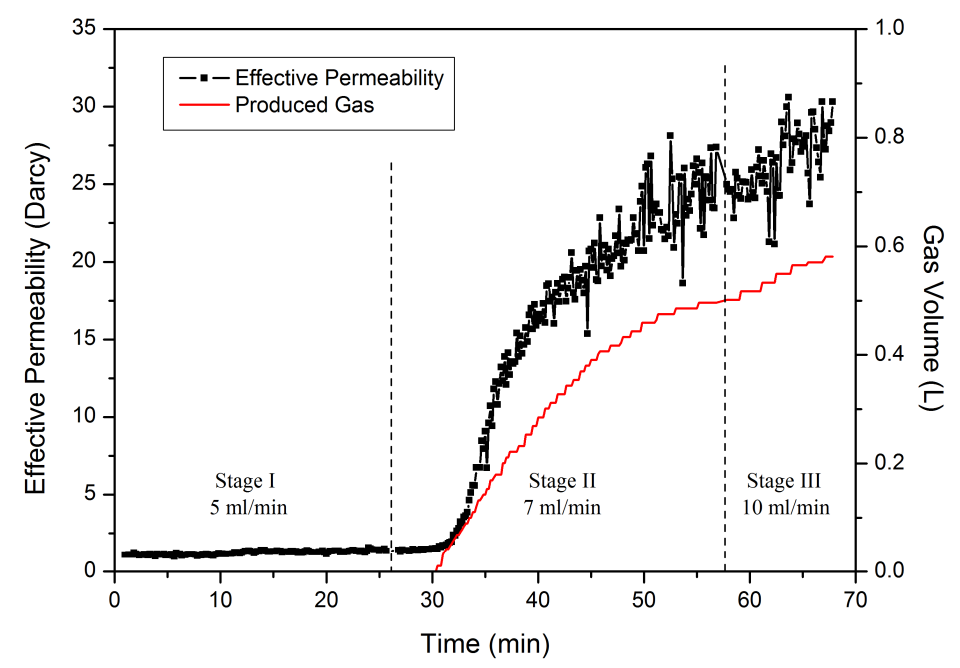

According to Equation (1), the reduction factor in this work is estimated to be about 38.0, which is in the same order of magnitude as the numerical estimations of Sakamoto et al. [21] Besides, previous experimental results of Minagawa et al. [19] show that the water permeability is strongly dependent on the grain size distribution, and the reduction factor increases with the increase of $k_{0}$. In their study, $n$ rises from 2.5 to 9.8 when $k_{0}$ increases from 0.08 to 10.0 Darcies. The obtained $n$ in the present study is in accordance with this increasing tendency. This phenomenon may indicate that the hydrate particles tend to block the pore channels more obviously in coarse sand sediments under low hydrate saturations. According to Equation (3), the relative error of $k$ can be simply expressed as:

$$
\frac{d k}{k}=\frac{d Q}{Q}+\frac{d(\Delta P)}{\Delta P}
$$

so the relative deviation of the measured permeability is calculated to be about $5 \%$.

Generally, the method employed in this work has the following advantages: (i) the traditional displacement of gas by water in the initial flowing stage is no longer needed when the gas saturation is already small, and it can eliminate the possibility of hydrate dissociation caused by the displacement; (ii) the absolute permeability could be obtained immediately when the flow process is started, and a relatively long period of steady state of water flow could be realized; (iii) the mass of the three phases (gas, water, and hydrate) in the porous media could be precisely predetermined and controlled. However, it will take much more time for hydrate formation because of the limited gas-water contact area under the condition of extremely low $S_{\mathrm{G}}$.

\section{Conclusions}

In this study an experimental apparatus for water permeability measurements in hydrate-bearing sediments was designed. Hydrate is formed in the core sample with a specialized method of precisely 
controlling the amount of the injected methane gas. The hydrate formation process is described by the change characteristics of the gas and hydrate saturations. In order to reduce the obstructive effect of the gaseous phase on the water flow, gas saturation is controlled below a desired low level by injecting water multiple times during the hydrate formation process.

Because of the increased gas viscosity under high pressure conditions, the intrinsic permeability $k$ of the porous media tends to decline slightly when the system pressure is raised from 0 to $15.5 \mathrm{MPa}$, but the extent of the decrease is not obvious. The average $k_{0}$ is measured to be 49.2 Darcies. After hydrate formation in the core holder, different water injection rates are applied to the system in three stages. Relatively stable $\Delta P$ and $k_{\text {eff }}$ are obtained in Stage I with a low injection rate of $5 \mathrm{~mL} / \mathrm{min}$, while the hydrate dissociates continuously in Stages II and III when the pressure and temperature conditions are still favorable for hydrate stability. In order to obtain a steady flow process in the hydrate-bearing sediments, it is necessary to control the $Q$ within a proper range to reduce the hydrate dissolution and dissociation rates. The absolute permeability of the porous sample is measured to be about 1.2 Darcies with 9.3\% hydrate saturation, and the reduction factor in this system is estimated to be about 38.0.

\section{Acknowledgment}

This work was supported by National Science Fund for Distinguished Young Scholars of China (Grant 51225603), National Natural Science Foundation of China (51076155, 51004089 and 51106160), Science \& Technology Program of Guangzhou (2012J5100012), Key Arrangement Programs of the Chinese Academy of Sciences (Grants KGZD-EW-301-2) and National Marine Geology Fund of China (GHZ2012006003), which are gratefully acknowledged.

\section{Conflict of Interest}

The authors declare no conflict of interest.

\section{References}

1. Sloan, E.D.; Koh, C.A. Clathrate Hydrates of Natural Gases, 3rd ed.; CRC Press: Boca Raton, FL, USA, 2008.

2. Collett, T.S. Gas hydrates as a future energy resource. Geotimes 2004, 49, 24-27.

3. Boswell, R.; Collett, T.S. Current perspectives on gas hydrate resources. Energy Environ. Sci. 2011, 4, 1206-1215.

4. Moridis, G.J.; Silpngarmlert, S.; Reagan, M.T.; Collett, T.S.; Zhang, K.N. Gas production from a cold, stratigraphically-bounded gas hydrate deposit at the Mount Elbert Gas Hydrate Stratigraphic Test Well, Alaska North Slope: Implications of uncertainties. Mar. Pet. Geol. 2011, 28, 517-534.

5. Xiong, L.J.; Li, X.S.; Wang, Y.; Xu, C.G. Experimental study on methane hydrate dissociation by depressurization in porous sediments. Energies 2012, 5, 518-530.

6. Ruan, X.K.; Song, Y.C.; Zhao, J.F.; Liang, H.F.; Yang, M.J.; Li, Y.H. Numerical simulation of methane production from hydrates induced by different depressurizing approaches. Energies 2012, 5, 438-458. 
7. Li, G.; Li, B.; Li, X.S.; Zhang, Y.; Wang, Y. Experimental and numerical studies on gas production from methane hydrate in porous media by depressurization in pilot-scale hydrate simulator. Energy Fuels 2012, 26, 6300-6310.

8. Fitzgerald, G.C.; Castaldi, M.J.; Zhou, Y. Large scale reactor details and results for the formation and decomposition of methane hydrates via thermal stimulation dissociation. J. Pet. Sci. Eng. 2012, 94-95, 19-27.

9. Su, Z.; Cao, Y.C.; Wu, N.Y.; He, Y. Numerical analysis on gas production efficiency from hydrate deposits by thermal stimulation: Application to the Shenhu Area, south China sea. Energies 2011, 4, 294-313.

10. Li, G.; Li, X.S.; Tang, L.G.; Zhang, Y. Experimental investigation of production behavior of methane hydrate under ethylene glycol stimulation in unconsolidated sediment. Energy Fuels 2007, 21, 3388-3393.

11. Li, B.; Li, G.; Li, X.S.; Li, Q.P.; Yang, B.; Zhang, Y.; Chen, Z.Y. Gas production from methane hydrate in a pilot-scale hydrate simulator using the huff and puff method by experimental and numerical studies. Energy Fuels 2012, 26, 7183-7194.

12. Li, X.S.; Li, B.; Li, G.; Yang, B. Numerical simulation of gas production potential from permafrost hydrate deposits by huff and puff method in a single horizontal well in Qilian Mountain, Qinghai province. Energy 2012, 40, 59-75.

13. Schicks, J.M.; Spangenberg, E.; Giese, R.; Steinhauer, B.; Klump, J.; Luzi, M. New approaches for the production of hydrocarbons from hydrate bearing sediments. Energies 2011, 4, 151-172.

14. Deusner, C.; Bigalke, N.; Kossel, E.; Haeckel, M. Methane production from gas hydrate deposits through injection of supercritical $\mathrm{CO}_{2}$. Energies 2012, 5, 2112-2140.

15. Moridis, G.J.; Reagan, M.T.; Boyle, K.L.; Zhang, K.N. Evaluation of the gas production potential of some particularly challenging types of oceanic hydrate deposits. Transp. Porous Media 2011, 90, 269-299.

16. Moridis, G.J.; Kowalsky, M.B.; Pruess, K. TOUGH+HYDRATE v1.1 User's Manual: A Code for the Simulation of System Behavior in Hydrate-Bearing Geologic Media; Lawrence Berkeley National laboratory: Berkeley, CA, USA, 2009.

17. Masuda, Y.; Naganawa, S.; Ando, S.; Sato, K. Numerical Calculation of Gas Production Performance from Reservoirs Containing Natural Gas Hydrates; Paper 38291; Society of Petroleum Engineers: San Antonio, TX, USA, 1997.

18. Leverett, M.C. Capillary behavior in porous solids. Trans. Soc. Pet. Eng. 1941, 142, 152-169.

19. Minagawa, H.; Ohmura, R.; Kamata, Y.; Ebinuma, T.; Narita, H.; Masuda, Y. Water Permeability Measurements of Gas Hydrate-Bearing Sediments. In Proceedings of the 5th International Conference on Gas Hydrates, Trondheim, Norway, 12-16 June 2005.

20. Kumar, A.; Maini, B.; Bishnoi, P.R.; Clarke, M.; Zatsepina, O.; Srinivasan, S. Experimental determination of permeability in the presence of hydrates and its effect on the dissociation characteristics of gas hydrates in porous media. J. Pet. Sci. Eng. 2010, 70, 114-122.

21. Sakamoto, Y.; Komai, T.; Miyazaki, K.; Tenma, N.; Yamaguchi, T.; Zyvoloski, G. Laboratory-scale experiments of the methane hydrate dissociation process in a porous media and numerical study for the estimation of permeability in methane hydrate reservoir. J. Thermodyn. 2010, 2010, doi:10.1155/2010/452326. 
22. Johnson, A.; Patil, S.; Dandekar, A. Experimental investigation of gas-water relative permeability for gas-hydrate-bearing sediments from the Mount Elbert Gas Hydrate Stratigraphic Test Well, Alaska North Slope. Mar. Pet. Geol. 2011, 28, 419-426.

23. Jin, Y.; Hayashi, J.; Nagao, J.; Suzuki, K.; Minagawa, H.; Ebinuma, T.; Narita, H. New method of assessing absolute permeability of natural methane hydrate sediments by microfocus X-ray computed tomography. Jpn. J. Appl. Phys. 2007, 46, 3159-3162.

24. Minagawa, H.; Nishikawa, Y.; Ikeda, I.; Miyazaki, K.; Takahara, N.; Sakamoto, Y.; Komai, T.; Narita, H. Characterization of sand sediment by pore size distribution and permeability using proton nuclear magnetic resonance measurement. J. Geophys. Res. 2008, 113. DOI: 10.1029/2007JB005403.

25. Waite, W.F.; Santamarina, J.C.; Cortes, D.D.; Dugan, B.; Espinoza, D.N.; Germaine, J.; Jang, J.; Jung, J.W.; Kneafsey, T.J.; Shin, H.; et al. Physical properties of hydrate-bearing sediments. Rev. Geophys. 2009, 47. DOI: 10.1029/2008RG000279.

(C) 2013 by the authors; licensee MDPI, Basel, Switzerland. This article is an open access article distributed under the terms and conditions of the Creative Commons Attribution license (http://creativecommons.org/licenses/by/3.0/). 